ACCEPTED MANUSCRIPT

\title{
Sustainable nitrogen fixation from synergistic effect of photo- electrochemical water splitting and atmospheric pressure N2 plasma
}

To cite this article before publication: Pradeep Lamichhane et al 2020 Plasma Sources Sci. Technol. in press https://doi.org/10.1088/1361$\underline{6595 / a b 7 f 4 d}$

\author{
Manuscript version: Accepted Manuscript \\ Accepted Manuscript is "the version of the article accepted for publication including all changes made as a result of the peer review process, \\ and which may also include the addition to the article by IOP Publishing of a header, an article ID, a cover sheet and/or an 'Accepted \\ Manuscript' watermark, but excluding any other editing, typesetting or other changes made by IOP Publishing and/or its licensors" \\ This Accepted Manuscript is @ 2020 IOP Publishing Ltd.
}

During the embargo period (the 12 month period from the publication of the Version of Record of this article), the Accepted Manuscript is fully protected by copyright and cannot be reused or reposted elsewhere.

As the Version of Record of this article is going to be / has been published on a subscription basis, this Accepted Manuscript is available for reuse under a CC BY-NC-ND 3.0 licence after the 12 month embargo period.

After the embargo period, everyone is permitted to use copy and redistribute this article for non-commercial purposes only, provided that they adhere to all the terms of the licence https://creativecommons.org/licences/by-nc-nd/3.0

Although reasonable endeavours have been taken to obtain all necessary permissions from third parties to include their copyrighted content within this article, their full citation and copyright line may not be present in this Accepted Manuscript version. Before using any content from this article, please refer to the Version of Record on IOPscience once published for full citation and copyright details, as permissions will likely be required. All third party content is fully copyright protected, unless specifically stated otherwise in the figure caption in the Version of Record.

View the article online for updates and enhancements. 


\title{
Sustainable nitrogen fixation from synergistic effect of photo-electrochemical water splitting and atmospheric pressure $N_{2}$ plasma
}

Pradeep Lamichhane ${ }^{1}$, Bishwa Chandra Adhikari ${ }^{1}$, Linh N. Nguyen $^{1}$, Ramhari Paneru ${ }^{1}$, Bhagirath Ghimire ${ }^{2}$, Sohail Mumtaz $^{1}$, Jun Sup Lim ${ }^{1}$, Hong, Young June ${ }^{1}$ and Eun Ha $\mathrm{Choi}^{1}$

${ }^{1}$ Department of Electrical and Biological Physics, Plasma Bio-science Research Centre, Kwangwoon University, Seoul, Republic of Korea.

${ }^{2}$ Materials Science Institute and Department of Chemistry, The University of Lancaster, City of Lancaster LA1 4YW, United Kingdom.

E-mail: ehchoi@kw.ac.kr

March 2020

\begin{abstract}
In this study, nitrogen fixation in the electrolyte was achieved by atmospheric pressure non-thermal plasma generated by a sinusoidal power supply (with an applied voltage of $10 \mathrm{kV}$ and frequency of $33 \mathrm{kHz}$ ). Ammonia measurements on plasma exposed electrolyte at several working gas and purging gas conditions revealed that nitrogen plasma on the same gas environment is more favorable for plasma-assisted ammonia synthesis. In addition, photo-electrochemical water splitting was performed by irradiating UV light $(316 \mathrm{~nm})$ on a titanium dioxide semiconductor photo-anode to generate hydrogen donor in nitrogen reduction reaction. The amount of ammonia synthesized by this synergistic process of photo-electrochemical water splitting and nitrogen plasma is six times higher than that obtained by nitrogen plasma alone. An increase in the co-synthesized $N O_{X}$ concentrations and background contamination at reaction site reduces the ammonia synthesis rate and Faraday efficiency. However, the ammonia production efficiency was increased up to $72 \%$ by using a proton-exchange membrane which prevent the diffusion of oxygen evolved from water splitting into the plasma, and by reducing the axial distance between the plasma electrode and reaction site. The sustainable nitrogen fixation process reported herein can be performed at atmospheric pressure conditions without a direct input of hydrogen gas or any catalyst.
\end{abstract}

Keywords: nitrogen fixation, non-thermal plasma, Ammonia synthesis, water splitting, nitrogen reduction reaction

\section{Introduction}

The route to industrial ammonia $\left(\mathrm{NH}_{3}\right)$ synthesis was opened by two Nobel laureates, Eritz Haber and Carl Bosch, in the early twentieth century, and the method is known as 
Haber-Bosch (H-B) process [1]. About 136 million tons of $N H_{3}$ is produced annually by this process, which covers $29 \%$ of total nitrogen fixation on earth and directly benefits approximately $40 \%$ of the world's population $[1,2,3,4]$. Currently, approximately $80 \%$ of the $\mathrm{NH}_{3}$ produced worldwide is utilized for nitrogen based manure generation [5]. The other uses of $\mathrm{NH}_{3}$ are explosives, pesticides, dyes, medicine, etc. Recently, other creative uses of $\mathrm{NH}_{3}$ are being seriously considered, including refrigeration, fermentation, and energy storage [2]. The $\mathrm{H}-\mathrm{B}$ process starts with the breakdown of nitrogen $\left(N_{2}\right)$ triple bond [6], which is a very strong bond owing to its high bond dissociation energy of $9.1 \mathrm{eV}\left(8.7 \times 10^{5} \mathrm{Jmol}^{-1}\right)$, and ionization energy of $14.53 \mathrm{eV}\left(1.39 \times 10^{6} \mathrm{Jmol}^{-1}\right)$ [7]. This nitrogen atom reacts with hydrogen gas $\left(H_{2}\right)$ over an iron-based catalyst under pressures of $150-300 \mathrm{~atm}$ and temperatures of $400-500^{\circ} \mathrm{C}$ [8]. $\mathrm{NH}_{3}$ producing industries consume $80 \%$ of the total energy demand in the chemical industry to overcome these extreme physical conditions [9]. These intensive energy and cost requirements led to the centralization of the $\mathrm{NH}_{3}$ yield industry. Furthermore, the steam reforming of petroleum for hydrogen production involves the use of $2 \%$ of worldwide petroleum, releasing more than 200 million tons of carbon dioxide $\left(\mathrm{CO}_{2}\right)$ gas each year, which corresponds to approximately $75 \%$ of total annual greenhouse gas generation on earth $[5,9,10]$. Therefore, scientists are seeking an alternative that can overcome these inadequacies of the $\mathrm{H}-\mathrm{B}$ process.

The numerous studies on non-thermal atmospheric pressure plasma (NTAPP) suggested that it is a potential alternative to the high-temperature and pressure technique for the synthesis of numerous compounds such as benzene and isooctane $[2,11,12,13,14]$. Nowadays, the electrochemical reduction of nitrogen to ammonia induced by plasma sources is seen as an alluring hitherto alternative to the $\mathrm{H}-\mathrm{B}$ process [8]. The main advantages of plasma-assisted nitrogen fixation are that it obviates the necessity of extremely high temperatures and pressures, requires renewable energy sources, and avoids the emission of greenhouse gases like $\mathrm{CO}_{2}[9,15]$. In non-thermal plasma, the electron temperature is in the range of few-electron volts [16]. The impact collision between the $N_{2}(N \equiv N)$ and electrons $\left(e^{-}\right)$has sufficient energy to break or weaken the triple bond of $N_{2}$ [16]. The weakened triple bond can then be broken with additional energy provided by the NTAPP. These atomic nitrogen react with the hydrogen ions $\left(\mathrm{H}^{+}\right)$in the plasma and the plasma/liquid $(\mathrm{P} / \mathrm{L})$ interface, thus forming $\mathrm{NH}_{3}[17,16]$ in the presence of aqueous electrons $\left(e_{a q}^{-}\right)[8]$.

In most of the studies on plasma-assisted $\mathrm{NH}_{3}$ synthesis, the process starts with
the hydrogen evolution reaction (HER) from plasma exposed water/liquid via ultravio-
let (UV) irradiation [6, 7, 9], electrolysis [3], electrocatalytic [18], electrochemical [8, 19], or direct chemical reactions [20]. This evolved hydrogen reduces the plasma generated atomic and vibrationally excited nitrogen into ammonia. The main reaction pathways of plasma-assisted nitrogen fixation is summarized in figure 1. However, the development of a method for an efficient HER from a sustainable and low-cost process is of great 


\section{Experimental setup and methodology}

Figure 2(a) schematically illustrates the concept of our four electrode configuration used for sustainable plasma-assisted nitrogen fixation. A custom built plasma jet was fabricated by inserting a stainless steel syringe electrode with a length of $40 \mathrm{~mm}$ and outer and inner diameters of $0.9 \mathrm{~mm}$ and $0.6 \mathrm{~mm}$, respectively, inside a quartz tube of length $56 \mathrm{~mm}$ and outer and inner diameters of $4 \mathrm{~mm}$ and $2 \mathrm{~mm}$, respectively. A $2 \mathrm{~mm}$ wide copper tape was used for peripheral ground by wrapping around the quartz tube, which is located $5 \mathrm{~mm}$ below the needle electrode. To synthesize $\mathrm{NH}_{3}$ in the electrolyte, a glass reaction cell sealed with a polystyrene lid was prepared and a portion (10 $\mathrm{mm}$ ) of quartz tube $3 \mathrm{~mm}$ below the ground was inserted through the lid and the distance of surface of the electrolyte and nozzle of the quartz tube was maintained at $3 \mathrm{~mm}$ unless it is stated. Unlike the other common plasma-assisted nitrogen fixation processes such as lightning and the Birkeland-Eyde process [29, 30], two holes were also drilled for the inlet and outlet of the purge gas with a flow rate of $2000 \mathrm{sccm}$ to remove the background contamination. When working gas with a flow rate of $1000 \mathrm{sccm}$ was supplied with an alternating sinusoidal voltage of $\sim 10 \mathrm{kV}$ (peak) to the syringe electrode with 
(a)

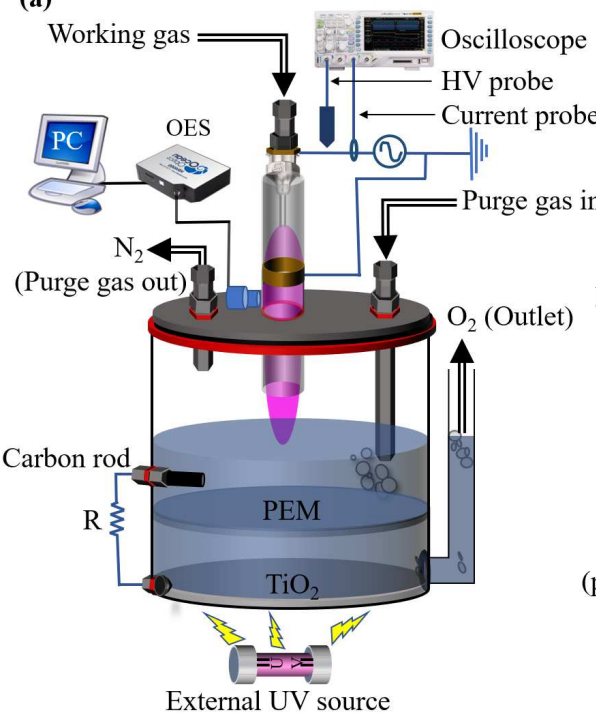

a repetition frequency (f) of $33 \mathrm{kHz}$, plasma was generated between the high-yoltage syringe electrode and the copper ground electrode and propagated along the direction of working gas flow to reach the electrolyte surface.

(b)

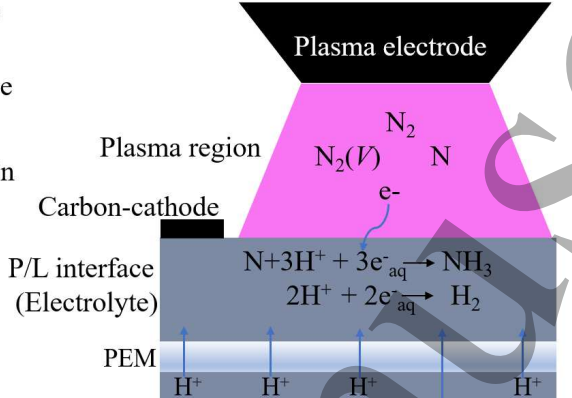

(c)

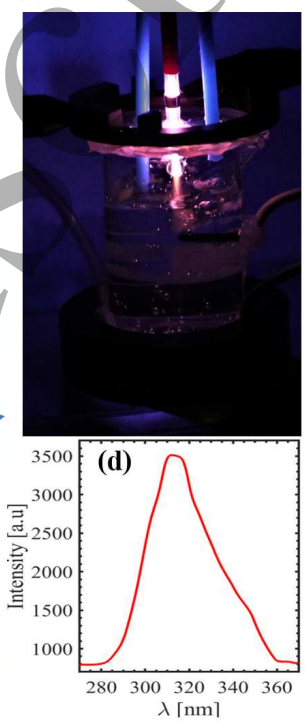

Figure 2. (a) Schematic diagram of $N_{2}$ plasma jet impinging on the electrolyte at the cathode side of the photo-electrochemical water splitting reaction cell together with a proton exchange membrane (PEM). (b) Potentially important species in the plasma region are vibrationally excited $N_{2}$ species and atomic nitrogen $(\mathrm{N})$, and those in the water are aqueous electrons $\left(e_{a q}^{-}\right)$and $H^{+}$transported through the PEM. The overall reactions involved in the nitrogen reduction reaction generating $\mathrm{NH}_{3}$ in the $\mathrm{P} / \mathrm{L}$ interfacial region are shown. (c) Photograph of the experimental setup. (d) Optical spectrum of UV sourcê used in experiment.

To achieve the HER through photo-electrochemical water splitting, two other electrodes were constructed for the photo-electrochemical reaction cell (PECRC). Generally, PECRC for water splitting is made up of UV exposed photo-anode, photo-cathode and electrolyte. A 0.05 -cm-thick circular $\mathrm{TiO}_{2}$ layer with a diameter of $3.8 \mathrm{~cm}$ coated over the glass substrate was used as the anode of the cell. This anode completely covered the bottom of the reaction cell. A carbon rod was used as the cathode of the cell, and both the electrodes were immersed in $40 \mathrm{ml}$ of $0.01 \mathrm{M} \mathrm{H}_{2} \mathrm{SO}_{4}$ electrolyte $(p H \sim 2)$. The cell anode was irradiated with a UV lamp (Sankyo Denki G4TE5, Japan) of $15 \mathrm{~W}$ and a peak wavelength of $319 \mathrm{~nm}(3.9 \mathrm{eV})$ from the bottom of the reaction cell for effective disassociation of water into oxygen and protons $\left(\mathrm{H}^{+}\right)$. For selective transportation of $H^{+}$from the anode to the cathode, a $25.4 \mu m$-thick Nafion 211 film used as a proton exchange membrane (PEM) was placed in the middle of the cell electrodes. We performed several experiments at different working and purging gas with and without UV, the cell electrodes, and PEM in the reaction cell and the obtained result was characterized by the corresponding nitrogen-based compounds formed in the plasma-exposed electrolyte. 
During the synergic interaction, the transport and reduction of $\mathrm{H}^{+}$at the cell cathode, and the interaction of the vibrationally excited nitrogen species or atomic nitrogen and electron coming from the nitrogen plasma with the hydrogen ion in the-plasma liquid (P/L) interface to form $\mathrm{NH}_{3}$ are shown in figure 2(b). Similarly, photograph of the experimental setup is shown in figure 2(c) and in figure 2(d) optical spectrum of UV lamp used in experiment is shown.

The discharge voltage and current were measured using a Tektronix P6015A highvoltage probe and a LeCroy CP030 current probe, respectively, and the measured voltage and current waveforms were monitored using 434 LeCroy wideband digital oscilloscopes. Photo-biased voltages and corresponding currents were measured by a multimeter (Fluke 287 true RMS multimeter) and recorded by a software (Fluke view forms). Optical emission spectroscopy (OES) was performed $3 \mathrm{~mm}$ below the peripheral ground using a HR4000+CG-UV-NIR (Ocean Optics, Inc.) spectrometer with the help of an optical fiber whose diameter is $400 \mu \mathrm{m}$. The spectrometer was/calibrated for wavelength measurements using a Hg-Ar lamp (Newport Corporation, model: 6048). Quantitative measurement of $\mathrm{NH}_{3}$ in the plasma exposed electrolyte was performed by a fluorometric method using a QuantiFluo ${ }^{T M}$ Ammonia Assay Kit (DNH3-200) (Bio-Assay Systems). The assay is based on an improved o-phthalaldehyde method [31]. This reagent reacts with $\mathrm{NH}_{3}$ and forms a fluorescent product. The fluorescence intensity $\left(\lambda_{\text {ex } / \text { em }}=360 / 450\right.$ $\mathrm{nm}$ ) is proportional to the $\mathrm{NH}_{3}$ concentration in the sample. Similarly, the quantitative colorimetric determination of $\mathrm{NO}_{x}\left(\mathrm{NO}_{2}^{-}\right.$, and $\left.\mathrm{NO}_{3}^{-}\right)$at $540 \mathrm{~nm}$ was performed using an improved Griess reagent kit [32] (BioAssay Systems, D2NO-100). The concentration of species in the electrolyte was determined from the calibration curves obtained from the absorbencies of compounds of known concentrations, which were determined following the manufacturer's instructions. Respective fluorescence and absorbance of the sample were measured by microplate reader (BioTeK Gen5). Similarly, Faradaic efficiency $(\eta)$ of $\mathrm{NH}_{3}$ synthesis measured in this experiment was calculated from the give relation [8].

$$
\eta[\%]=\frac{\text { Measured } \mathrm{NH}_{3} \text { concentration }}{\text { Faradaic } \mathrm{NH}_{3} \text { concentration }} \times 100 \% \text {. }
$$

Faradaic $\mathrm{NH}_{3}$ concentration $=\mathrm{q} / \mathrm{FnV}$. Here, $\mathrm{q}$ is for total charge flowing through the external circuit of reaction cell and F $\left(=96485 \mathrm{Cmol}^{-1}\right.$, is Faraday's constant, n (= 3 ) is the number of electron required for ammonia synthesis and V $(=40 \mathrm{ml})$ is total volume of electrolyte.

\section{Results}

\subsection{Electrical and optical characteristics of plasma}

The typical voltage and current waveforms of plasma discharge are shown in figure 3(a) The several discharge current (I) peaks in the rising part of the discharge voltage (V) are 
generated by the accumulation of wall charges $(\mathrm{Q})$ on the inner side of the quartz tube during discharge. These discharge currents were measured as a few tens of milliamperes with duration of a nanosecond to tens of nanoseconds. At the negative alternate of the voltage waveform, these accumulated charges were reversed in the negative voltage polarity, which generated similar current peaks in the negative direction. Plot of the corresponding charge $\left(Q=\int I d t\right)$ versus voltage (Lissajous figure) is shown in figure 3(b). When the applied voltage across the electrodes is not high enough to generate a plasma, the charge versus voltage plot shows a straight line. However, when the applied voltage is adequate to cause the discharge of $N_{2}$ gas, the charge in the circuit increases or decreases sharply according to the discharge. In this case, the Lissajous figure becomes a parallelogram and the area of the closed-loop (parallelogram) is equal to the discharge energy (E) dissipated in each cycle $[33,26]$. The power dissipated during discharge can be calculated by multiplying the area with frequency. The energy dissipated per cycle was calculated as follows [33]

$$
E=\int_{t=0}^{t=T} V I d t=A_{\text {lissajous }} .
$$
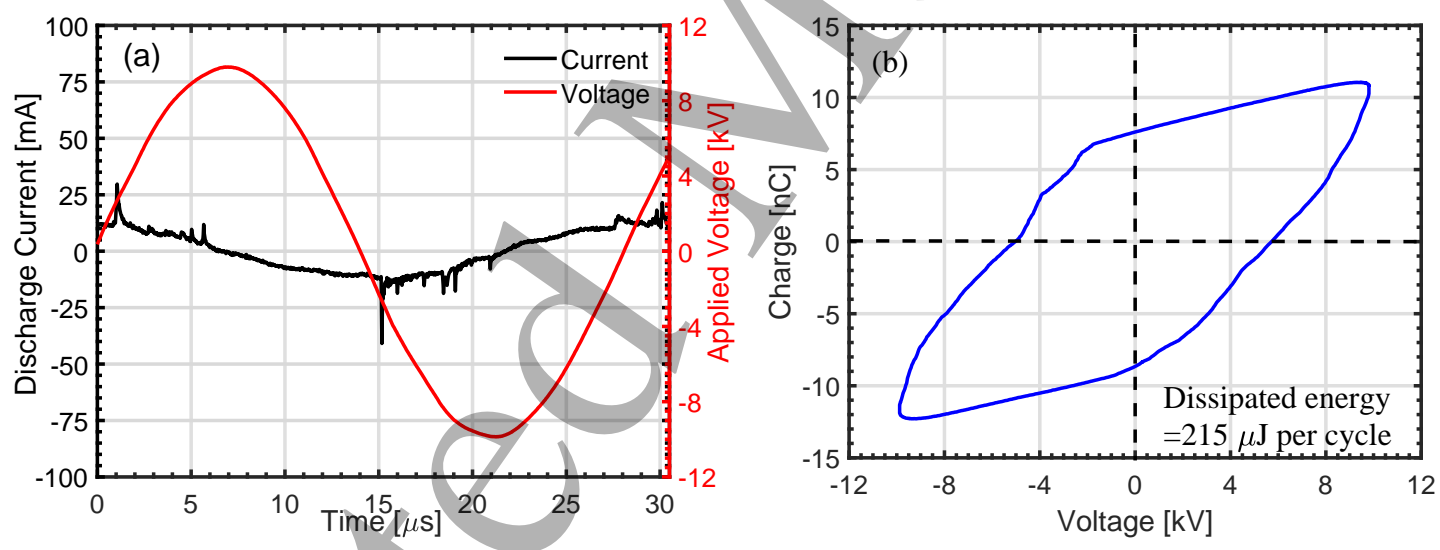

Figure 3. Electrical characteristics of discharge. (a) Current (black) and voltage (red) waveforms of discharge current versus time plot. (b) Plot of corresponding charge versus voltage. [Working gas: nitrogen; gas flow rate in the main tube: $1000 \mathrm{sccm}$.]

The area of the Lissajous figure in our experiment was calculated as $215 \mu \mathrm{J}$. All the plasma measurements were performed at an applied power of $P=E \times f=7.1 \mathrm{~W}$

Numerous reactive oxygen and nitrogen species are delivered during the plasma discharge in the air ambient. In the gas phase, depending on the injected energy, working and surrounding gas, dissociation of working gases and water molecules by the energetic electrons in the discharge and UV photolysis mostly leading to the formation of various reactive oxygen and intro gen species including excited species through several reaction pathways. Figure 4 shows a typical optical emission spectrum of nitrogen plasma recorded $3 \mathrm{~mm}$ below the peripheral copper ground with 7.2 Watt plasma input power. The emission profile from 200 to $400 \mathrm{~nm}$ is mostly composed of reactive nitrogen 


\subsection{Total nitrogen fixation for various configurations and controls}

We initially performed a series of experiments to identify the most favourable working and purging gas condition for $\mathrm{NH}_{3}$ production. Figure 5 shows the average concentrations of $\mathrm{NH}_{3}$ and $\mathrm{NO}_{X}$ produced in the electrolyte after 30 minutes of plasma exposure for the following configurations: (i) Argon (Ar) gas is used for both working and purging gas; (ii) Ar plasma and air purging gas; (iii) Ar plasma and $N_{2}$ purging gas; (iv) $N_{2}$ plasma and Ar purging gas; ; (v) $N_{2}$ plasma and air purging gas; and ; (vi) $N_{2}$ is used for both working and purging gas; In this experiment, plasma was normally exposed on electrolyte without photo-electrochemical water splitting reaction cell and external UY source. In the complete set of data trials of Ar plasma, no detectable amount of $\mathrm{NH}_{3}$ was found. Here, as expected, main products are measured to be $N O_{X}$. As we $\mathrm{nm})$ corresponding to the transition $N_{2}\left(C^{3} \prod_{g}-B^{3} \prod_{g}\right)[35,36]$, and $N_{2}$ first negative system (FNS) (around $400 \mathrm{~nm}$ ) corresponding to the transition $N_{2}^{+}\left(B^{2} \sum_{u}^{+}-X^{2} \sum_{u}^{+}\right)$ [35]. A weak emission from hydroxyl radicals $(\mathrm{OH})$ corresponding to the transition $A^{2} \sum^{+}\left(v^{\prime \prime}=0\right)-X^{2} \Pi\left(v^{\prime \prime}=0\right)$ is also observed at $309 \mathrm{~nm}$ [35]. This is due to the dissociation of water molecules presents in the working gas by electrons or metastable atoms [37]. In addition to this, weak peaks atomic nitrogen at 742,822 , and 868 and atomic oxygen at $777 \mathrm{~nm}$ and $845 \mathrm{~nm}$ [38] has also been seen. For greater visualization, the range of 700-900 $\mathrm{nm}$ is magnified in the inset of Figure 4

Figure 4. Optical emission spectrum of plasma measured $3 \mathrm{~mm}$ downstream the peripheral ground. [Working gas: nitrogen; gas flow rate in the main tube: $1000 \mathrm{sccm}$; applied voltage: $10 \mathrm{kV}$; frequency: $33 \mathrm{kHz}$. 
manipulate the background argon gas by air and nitrogen in argon plasma, only $N O_{X}$ concentrations was measured to be increased but $\mathrm{NH}_{3}$ is still undeteactable/negligible. In contrast with Ar plasma, $\mathrm{NH}_{3}$ was also found to be increased with $N O_{X}$ in nitrogen plasma when we alter the argon background with air and nitrogen. In nitrogen plasma, the quantity of $\mathrm{NH}_{3}$ was small in comparison with $\mathrm{NO}_{X}$ however, it was significantly measurable. The $\mathrm{NH}_{3}$ synthesis rate in nitrogen plasma was increased by $50 \%$ when argon environment is altered by nitrogen environment. These measurements confirmed that $N_{2}$ plasma on the same gas environment notably enhanced the $\mathrm{NH}_{3}$ synthesis rate. On behalf of this result, in the proceeding experiment nitrogen gas is used for both working and purging gas.

The interaction of nitrogen plasma with water activates the production of different nitrogen based product in the water, which alters the chemical composition of water. Figure 6 shows the average concentrations of $\mathrm{NH}_{3}$ and $\mathrm{NO}_{x}$ produced in the electrolyte after 30 min of nitrogen plasma exposure at the following configurations: (i) only plasma without photo-electrochemical water splitting; (ii) plasma with UV exposure on electrolyte without photo-electrochemical water splitting; (iii) Combined effect of plasma and photo-electrochemical water splitting without PEM; (iv) Combined effect of plasma and photo-electrochemical water splitting with PEM; and (v) No plasma, only nitrogen gas is passed on photo-electrochemical water splitting reaction cell. Only $3 \mathrm{ppm} \mathrm{NH}_{3}$ was produced by only plasma, while the $N O_{X}$ concentration was approximately 6 times more than the $\mathrm{NH}_{3}$ concentration at this configuration. Next, when the plasma exposed 
electrolyte was also exposed by external UV light source from bottom of reaction cells as in configuration (ii), the $\mathrm{NH}_{3}$ concentration slightly increased to $8 \mathrm{ppm}$, whereas the $N O_{X}$ concentration drastically increased to $28 \mathrm{ppm}$. After that, plasma was exposed on the photo-electrochemical water splitting reaction cell without PEM, the $N O_{X}$ and $N H_{3}$ concentration further increased to $35 \mathrm{ppm}$ and $11 \mathrm{ppm}$, respectively. For configurations (i)-(iii), the $\mathrm{NH}_{3}$ concentrations were significantly lower than $\mathrm{NO}_{X}$ concentrations. However, after embedding a PEM inside the electrolyte of photo-electrochemical water splitting reaction cell as described in configuration (iv), the $\mathrm{NH}_{3}$ concentration was increased more sharply to $19 \mathrm{ppm}$ but $N O_{X}$ concentration was decreased to $15 \mathrm{ppm}$. In this configuration, $\mathrm{NH}_{3}$ leads the $\mathrm{NO}_{x}$ concentration, in contrast to the previous configuration. A comparison of configurations (iii) and (iv) revealed that the PEM is responsible for the increase in $\mathrm{NH}_{3}$ concentration by $72 \%$ and the decrease in $\mathrm{NO}_{x}$ concentration by $57 \%$. Besides this, to study the direct interaction between $N_{2}$ gas and the evolved hydrogen, $N_{2}$ gas was passed (without plasma) on photo-electrochemical water splitting reaction cell. No nitrogen-based product was detected in the electrolyte during this process.

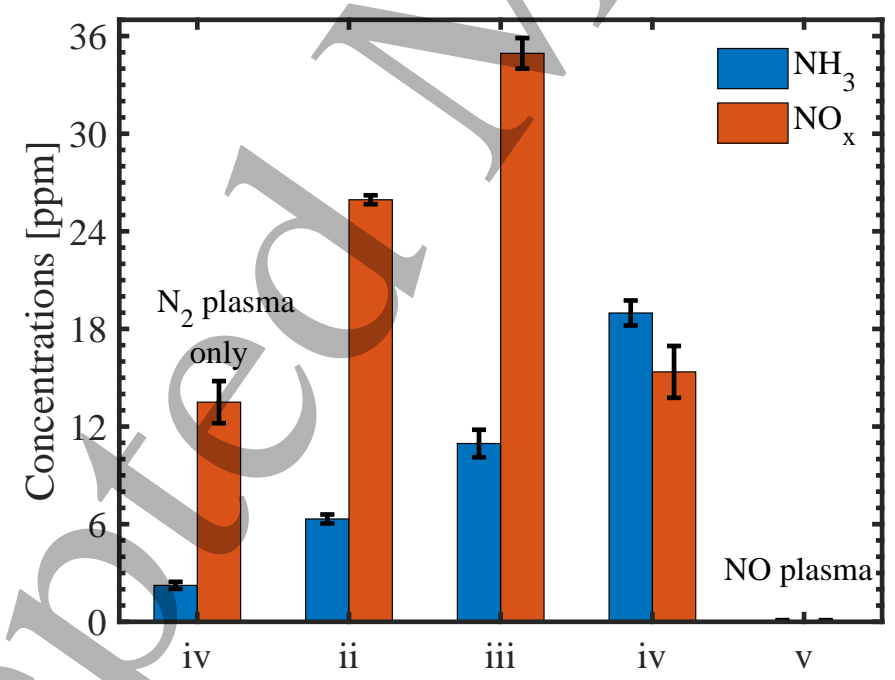

Figure 6. Concentrations of $\mathrm{NH}_{3}$ and $\mathrm{NO}_{X}$ produced in $40 \mathrm{ml}$ of acidic electrolyte during 30 min of plasma exposure for the following configurations: (i) only plasma without photo-electrochemical water splitting; (ii) plasma with UV exposure on electrolyte without photo-electrochemical water splitting; (iii) Combined effect of plasma and photo-electrochemical water splitting without PEM; (iv) Combined effect of plasma and photo-electrochemical water splitting with PEM; and (v) No plasma, only nitrogen gas is passed on photo-electrochemical water splitting reaction cell.

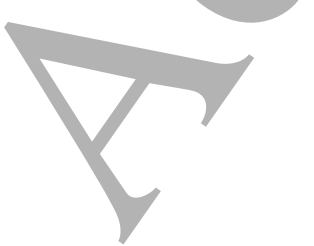
西 西 西 .

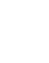

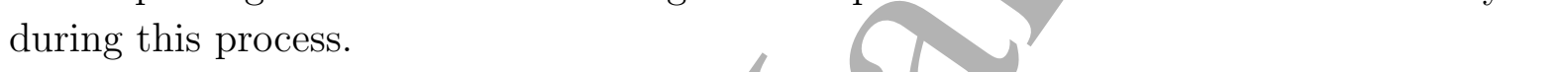



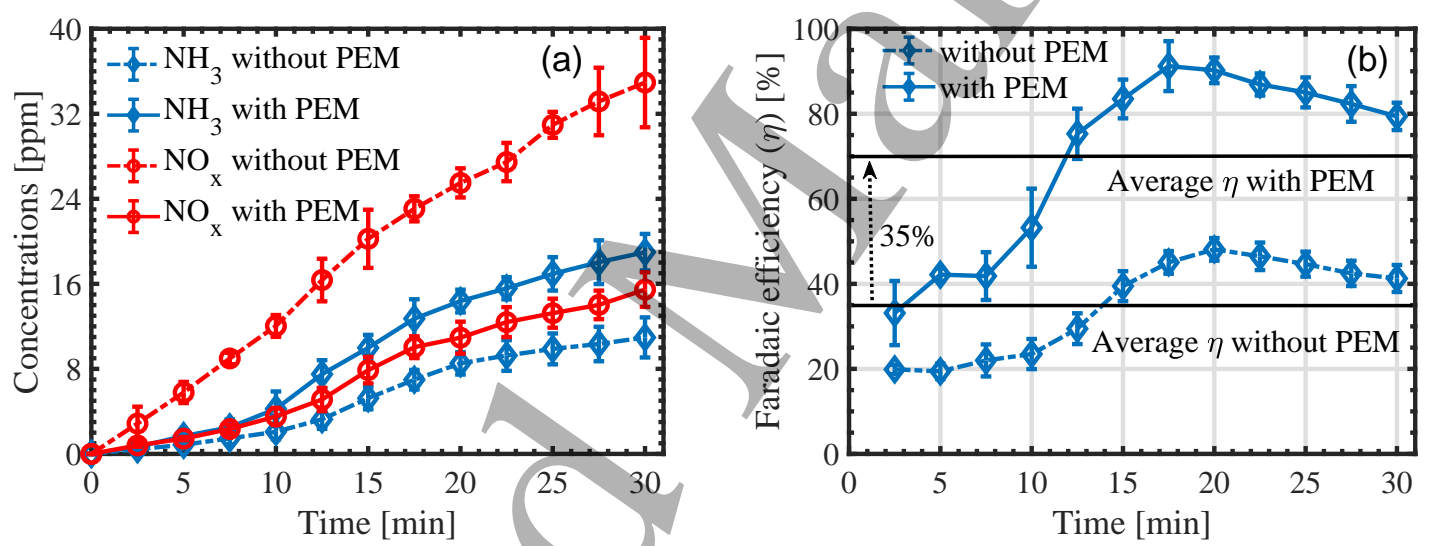

Figure 7. Temporal variations in (a) $N O_{X}$ and $N H_{3}$ concentrations (b)Faradaic efficiency for $\mathrm{NH}_{3}$ synthesis in the electrolyte during the synergistic interaction of photo-electrochemical water splitting and nitrogen plasma with and without PEM.

Next to this experiment, spatial variation of $\mathrm{NO}_{\mathrm{X}}$ and $\mathrm{NH}_{3}$ concentrations synthesized by the combined effect of nitrogen plasma and photo-electrochemical water splitting in presence of PEM was investigated and obtained result is presented in figure 8. Different from the aforementioned experiment, axial distance between the nozzle of the quartz tube and surface of the electrolyte $(Z)$ is varied by from $0-7 \mathrm{~mm}$ by shifting the plasma jet in upward direction (away from the electrolyte) in this experiment. From this result, Both $\mathrm{NO}_{x}$ and $\mathrm{NH}_{3}$ concentration in plasma exposed electrolyte decreased with increase in axial distance but $\mathrm{NH}_{3}$ concentration decreased more sharply than $\mathrm{NO}_{x}$ concentration. Here, the average concentration of $\mathrm{NO}_{x}$ and $\mathrm{NH}_{3}$ diminished by 2 and 3 fold every millimeter in axial direction, respectively. The average $\mathrm{NH}_{3}$ and $\mathrm{NO}_{X}$ concentrations decreased slowly while increasing the axial distance from o $\mathrm{mm}$ to $3 \mathrm{~mm}$, after that, it falls more sharply. As seen in figure 8 , at $\mathrm{z}=0 \mathrm{~mm} \mathrm{NH}$ concentrations was about $21 \mathrm{ppm}$ with high error but at $\mathrm{z}=3 \mathrm{~mm}$ it was about $19 \mathrm{ppm}$ 


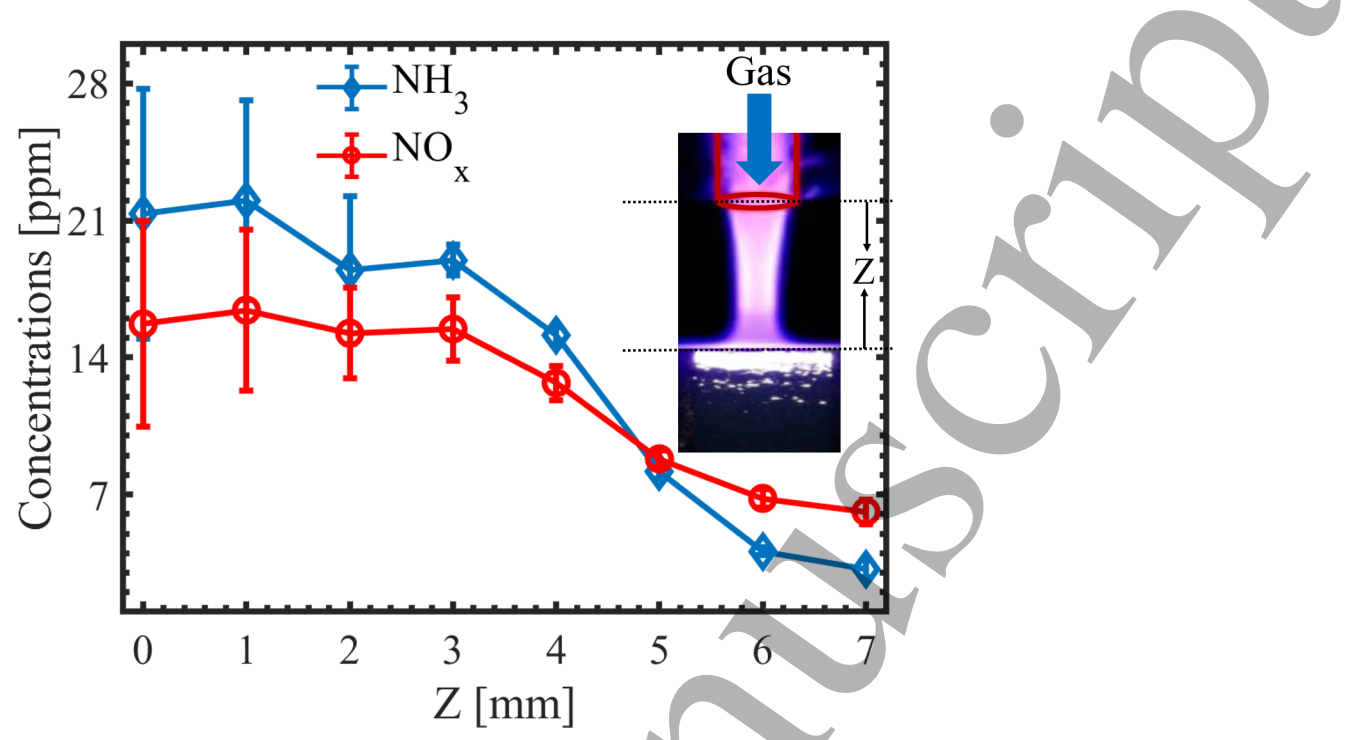

Figure 8. Spatial variation of $\mathrm{NO}_{X}$ and $\mathrm{NH}_{3}$ concentration synthesized by the synergistic of photo- electrochemical water splitting and plasma in nitrogen plasma exposed electrolyte in configuration.

with low error values. Afterward it was sharply reduced to $5 \mathrm{ppm}$ at $7 \mathrm{~mm}$. Thus, the moderate distance between the nozzle of the quartz tube and surface of the electrolyte is advantageous in this experiment to achieve a higher synthesis rate at greater consistency. In this experiment, when the nozzle of the quartz tube is very close to the surface of the electrolyte, plasma generation is disturbed by water droplets coming from the splash of water caused by the gas flow. As a result of this disturbance, highly fluctuated concentrations of $\mathrm{NH}_{3}$ and $\mathrm{NO}_{\mathrm{X}}$ was obtained at $\mathrm{z}<3 \mathrm{~mm}$.

\section{Discussion}

Photo-electrochemical water splitting converts photon energy into electrical energy in a cell comprising two electrodes immersed in an aqueous electrolyte. In this experiment, a semiconductor, $\mathrm{TiO}_{2}$, was used as the photo-anode and exposed to light for photon absorption, and a conductor, carbon rod, was used as the cathode. If the energy of the photon $(E=h \nu)$ is equal or greater than the band gap of $\mathrm{TiO}_{2}$, the electrons jump to the conduction band (CB), leaving holes in the valance band (VB) [23]. The lightinduced intrinsic ionization of $\mathrm{TiO}_{2}$ resulting in the formation of quasi-free electrons $\left(e^{-}\right)$in the $\mathrm{CB}$ and holes $\left(h^{+}\right)$in the VB is illustrated in figure 9(a). The band gap of $\mathrm{TiO}_{2}$ is approximately $3.2 \mathrm{eV}$ [21], and the threshold wavelength required to form a charge carrier pair in this semiconductor as shown in equation (3) is approximately 382 nm. [23].

$$
2 h \nu \rightarrow 2 e^{-}+2 h^{+} .
$$

Then, the photo-induced holes oxidized the water molecules into gaseous oxygen and hydrogen ions on the surface of $\mathrm{TiO}_{2}$, as presented in equation (4). The detailed 
mechanism of water oxidation at the oxygen vacancies present on the surface-active sites of $\mathrm{TiO}_{2}$ has been discussed elsewhere [21, 23].

$$
2 h^{+}+\mathrm{H}_{2} \mathrm{O} \rightarrow \frac{1}{2} \mathrm{O}_{2}+2 \mathrm{H}^{+} .
$$

Threshold energy $E_{t}$ required for equation (3) is [21]

$$
E_{t}=\frac{\Delta G_{\mathrm{H}_{2} \mathrm{O}}^{0}}{2 N_{A}}=\frac{237.141 \mathrm{kJmol}^{-1}}{2 \times 6.023 \times \mathrm{mol}^{-1}}=1.23 \mathrm{eV} .
$$

(a)

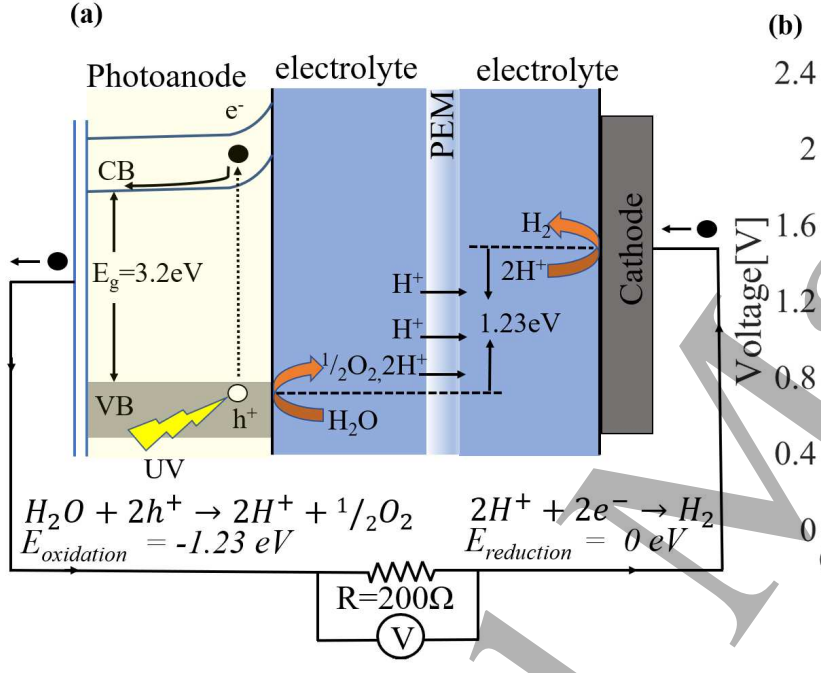

(b)

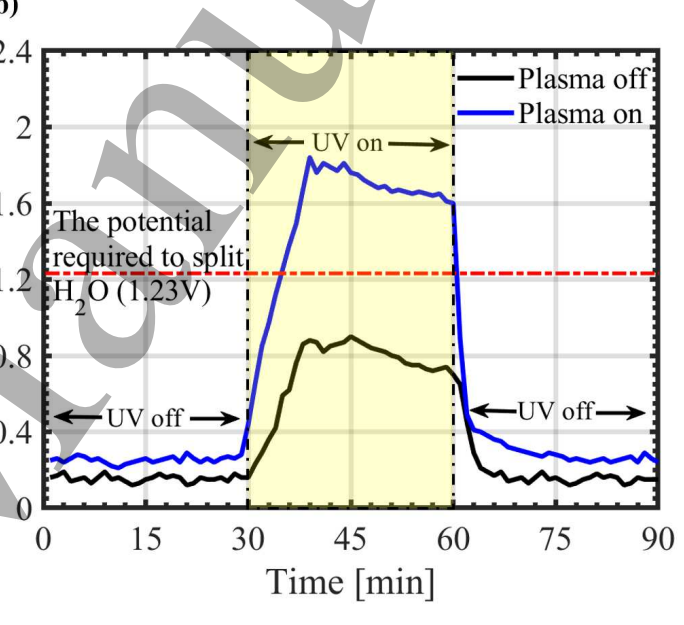

Figure 9. (a) Mechanism of electron-hole pair formation on $\mathrm{TiO}_{2}$ photo-anode by UV irradiation, oxidation of water at the photo-anode, transport of $H^{+}$through the PEM, and reduction of $\mathrm{H}^{+}$at the cathode. (b) Effect of UV-irradiated $\mathrm{TiO}_{2}$ with and without plasma exposure of the electrolyte on photo-biased voltage.

Where, $\Delta G_{\mathrm{H}_{2} \mathrm{O}}^{0}$ is the standard free enthalpy per mole of reaction and $N_{A}$ is Avogadro's number. Electrochemical water splitting is feasible only when the potential difference between the two cell electrodes is equal to or greater than 1.23 V. Even though the band gap of $\mathrm{TiO}_{2}$ is approximately $3.2 \mathrm{eV}$ [21], the photo-biased voltage between the two electrodes is only $\sim 0.7-0.9 \mathrm{~V}$ owing to its high corrosion resistance [21]. The effect of UV light on photo-biased voltages is shown in figure $9(\mathrm{~b})$. These plots were recorded during plasma off and plasma plume touching the electrolyte surface. As can be seen, the photo-biased voltage reached its maximum within a few minutes of exposing the photo-anode to UV and returned to its initial background value within a few seconds of switching off the UV light. The photo-biased voltage generated within the cell in the absence of plasma is less than that required for water decomposition as calculated by equation (5). After turning on plasma, when electrolyte is encountered by plasma at the cathode side of reaction cell, deposition of charge on the electrolyte contribute sufficient biased voltage for water splitting. In this presented result, photo-biased voltage of 1.8 
$\mathrm{V}$ was achieved that was enough for water decomposition. The oxygen evolved from equation (4) cannot diffuse through the PEM so it escapes out through the outlet from the anode side of the reaction cell. Only $H^{+}$ions transport toward the cathode in the cell through the PEM. At the same time, the electrons transfer to the external circuit and the cathode, where hydrogen ions $\left(H^{+}\right)$are reduced into hydrogen, as presented in equation (6) [25]

$$
2 \mathrm{H}^{+}+2 e^{-} \rightarrow \mathrm{H}_{2}
$$

The electrons generated by plasma also injected into the interfacial surface of the electrolyte [13]. These electrons are responsible for the formation of vibrationally excited nitrogen species and atomic nitrogen in the plasma phase through collision excitation, direct ionization, and step-wise ionization. Then, these electrons and vibrationally excited nitrogen species and atomic nitrogen transported to the aqueous electrolyte. The overall breakdown reaction of $N_{2}$ triple bond in the plasma phase is shown in equation (7). These nitrogen atoms could electrochemically combine with $H^{+}$and $e_{a q}^{-}$ at the plasma-liquid interface as in equation (8) [8, 39],

$$
\begin{aligned}
& N_{2}+e^{-} \rightarrow 2 N+e^{-} . \\
& N+3 H^{+}+3 e_{a q}^{-} \rightarrow \mathrm{NH}_{3} .
\end{aligned}
$$

Nitric oxide (NO), nitrite $\left(\mathrm{NO}_{2}\right)$ and nitrate $\left(\mathrm{NO}_{3}\right)$ can form in the plasma/plasmaliquid interface via several possible pathways. In the main reaction pathway, Reactive nitrogen species react with the $O \mathrm{H}$ radicals produced by plasma initiated UV photolysis $[40,41]$, as shown in equation (9) to form $\mathrm{NO}, \mathrm{NO}_{2}$ and $\mathrm{NO}_{2}$ via mechanism as in equations (10),(11) and (12) [9, 14]:

$$
\begin{aligned}
& \mathrm{H}_{2} \mathrm{O}+\mathrm{UV} \rightarrow \mathrm{H}+\mathrm{OH} . \\
& \mathrm{N}+\mathrm{OH} \rightarrow \mathrm{NO}+\mathrm{H} . \\
& \mathrm{NO}+\mathrm{OH} \rightarrow \mathrm{H}+\mathrm{NO}_{2} . \\
& \mathrm{NO}_{2}+\mathrm{OH} \rightarrow \mathrm{H}+\mathrm{NO}_{3} .
\end{aligned}
$$

The formed $N O_{X}$ species dissolved in the liquid transform very fast to $\mathrm{NO}_{2}^{-}$and $\mathrm{NO}_{3}^{-}$ through the equations (13) and (14) $[42,43]$

$$
\begin{aligned}
& \mathrm{NO}_{2}(a q)+\mathrm{NO}_{2}(a q)+\mathrm{H}_{2} \mathrm{O}(l) \rightarrow \mathrm{NO}_{2}^{-}+\mathrm{NO}_{3}^{-}+2 \mathrm{H}^{+} . \\
& \mathrm{NO}(a q)+\mathrm{NO}_{2}(a q)+\mathrm{H}_{2} \mathrm{O}(l) \rightarrow 2 \mathrm{NO}_{2}^{-}+2 \mathrm{H}^{+} .
\end{aligned}
$$

The formed $\mathrm{NH}_{3}$ will also immediately dissolve in the acidic electrolyte because the trapping of these nitrogen compounds is significantly higher in acidic media than in neutral and basic media [8]. The further increase in $N O_{X}$ concentrations in the absence of a PEM as seen in figure 6 and 7 is possibly due to Telestich's reactions [44] caused 
by the interaction of oxygen with the nitrogen plasma. Oxygen and hydrogen ion ions obtained from equation (4) or hydrogen atom from equation (6) directly interact with the nitrogen plasma at the interfacial region of the electrolyte and gas environment. The reactive nitrogen species tend to form more stable compounds in a liquid since the reactions in equations (10),(11) and (12) are faster than reaction in equation (8) [9] so main products obtained in the liquid phase were $N O_{X}$. Owing to the electron scavenging effect of dissolved $\mathrm{NO}_{X}$, the $\mathrm{NH}_{3}$ concentration further decreased with an increase in $N O_{X}$ concentration.

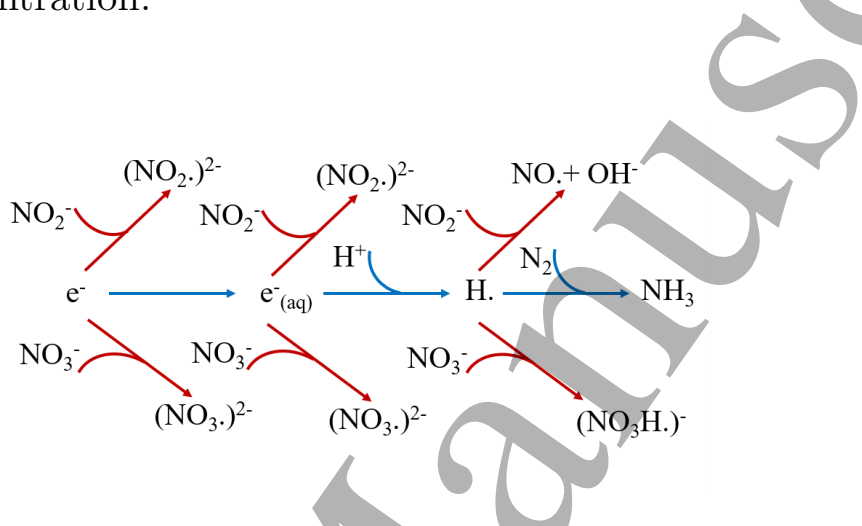

Figure 10. Ammonia production pathway (blue) together with $e^{-}$and $\mathrm{H}$ scavenging reactions of dissolved $\mathrm{NO}_{2}$ and $\mathrm{NO}_{3}$ (red)

The crucial role of aqueous electrons $\left(e_{a q}^{-}\right)$on $\mathrm{NH}_{3}$ synthesis has already been verified by scavenging experiments elsewhere [8]. The scavenging effect and the formation of other new reducing radical species such as $\left(\mathrm{NO}_{2}\right)^{2-},\left(\mathrm{NO}_{3}\right)^{2-}$ are presented in figure 10. The high reactivity of dissolved $N O_{X}$ with $e_{a q}^{-}$could effectively control the formation of $\mathrm{NH}_{3}$ because the absorption rate of the electron by $N O_{X}$ (red reactions in figure 10) is 500 times faster than $\mathrm{N}$ and $\mathrm{H}$ combination [8] (blue reactions in figure 10). The decrease in $N O_{X}$ concentrations in the presence of a PEM, as seen in the results of figure 6 and 7 is attributed to the extinct Zeldovich's reactions at the reaction site due to a lack of surrounding environment of oxygen; subsequently, more $\mathrm{NH}_{3}$ was formed and it became the dominant nitrogenous compound in the electrolyte. Distribution of $\mathrm{NH}_{3}$ and $N O_{X}$ concentrations is directly affected by electron density, energy and abundance of the reactive nitrogen species. It has been also reported that, energy, electron density and the reactive species generated by plasma jet are delivered to the electrolyte which is higher at lower axial distance and continuously decrease with the downstream propagation of plasma plume [45]. In this presented work, the electron density continuously reduced from $5.23 \times 10^{13} \mathrm{~cm}^{-13}$ to $1.17 \times 10^{13} \mathrm{~cm}^{-13}$ with increase in axial distance from o $\mathrm{mm}$ to $7 \mathrm{~mm}$, respectively. Which has been measured using a method described in our previous publication [37]. Electrons delivered to the electrolyte is a major source of solvated electron $\left(e_{a q}^{-}\right.$. $)$therefore the rate of $\mathrm{NH}_{3}$ formation is decreased with increase in axial distance as seen in the figure 8

Considering their performance, the HER from the photo-electrochemical water 
splitting was better than that from the electrolysis of water [3], electrochemical reduction of water $[8,19]$, and UV induced dissociation of water $[6,7,9]$ for $\mathrm{NH}_{3}$ synthesis. A commercial membrane electrode assembly (MEA) electrolyzer is available for electrochemical water splitting; however, according to Kumari et al. [3], the direct plasma exposure of the costly MEA electrolyzer causes several drawbacks such as the gradual degradation of MEA performance via a sputtering mechanism, dehydration of electrode, and difficulties in the stabilization of current after plasma exposure. Nevertheless, in this photo-electrochemical water splitting, the current stabilized within 2-5 minutes and no physicochemical change was observed in the PEM after the operation, which was confirmed by contact angle measurements. The contact angle of PEM did not change and was $73.16^{0} \pm 0.53^{0}$ before and after the 4-hour operation. Next, superiority of our experiment over others previously reported HER technique $[3,19,6,7,9]$ is also verified by Faradaic efficiency measurement as presented in figure 7(b). The average Faradaic efficiency of $\mathrm{NH}_{3}$ synthesis in this experiment is surprisingly higher than those of other previously reported plasma-assisted nitrogen fixations (2-60\%) [15, 46, 47, 48] and also quite stable than the report of Hawtof et al. [8].

The energy consumption of the $\mathrm{H}-\mathrm{B}$ process is approximately $9-13 \mathrm{kWhkg}^{-1}[1,8]$ using natural gas, coal, or fuel oil as feedstock. However, in this experiment, the energy consumption (= Power $/ \mathrm{NH}_{3}$ production rate) was $\sim 4500 \mathrm{kWhkg}^{-1}$, which is much higher than that of the $\mathrm{H}-\mathrm{B}$ process and lower than that of other previously reported plasma-assisted $\mathrm{NH}_{3}$ synthesis process $\left(\sim 17000 \mathrm{kWhkg}^{-1}\right.$ [46]. Plasma-assisted $\mathrm{NH}_{3}$ synthesis could be a potential competitor of the $\mathrm{H}-\mathrm{B}$ process if the Faradaic efficiency can be improved by the selective production of $\mathrm{NH}_{3}$, which remains a challenge $[49,50]$ because plasma simultaneously produces a bulk variety of by-products. $H_{2}$ resources will not remain a challenge in the future because water splitting has great potential similar to the steam transformation of petroleum [21, 22, 23, 24]. Thus, we developed a novel method that integrates the photo-electrochemical water splitting method with a plasma system for nitrogen fixation and obtained expected results. In our experiment, $\mathrm{NH}_{3}$ is the desired product; however, the concentrations of $N O_{x}$ formed in the electrolyte were also analyzed, which could add extra value to the nitrogenous compound. It is obvious that a higher selectivity is required in the cell, which could be achieved using a catalyst in the future. Nevertheless, our approach could be a milestone for applying the HER via photo-electrochemical water splitting in plasma-assisted NRR to ammonia. Considering the overall cost associated with the establishment, production, transportation, and storage, the plasma technology could be an economic and environment friendly approach for localized small-scale production of ammonia at a site of use such as farmland.

\section{Conclusions}

In this experiment, the cathode side of the electrolyte was exposed to non-thermal atmospheric pressure nitrogen plasma in a photo-electrochemical water-splitting 
reaction cell. The atomic nitrogen generated from plasma electrochemically react with the hydrogen ion generated from UV-induced water oxidation at the $\mathrm{TiO}_{2}$ photoanode. A practical advantage of this method is that ammonia can be achieved from nitrogen gas and water at ordinary temperatures and pressures without any catalyst and sacrificial reagent. The interaction of vibrationally excited nitrogen species generated by plasma with the oxygen evolved from the water dissociated is responsible for the higher concentration of $N O_{X}$ in the absence of a PEM. However, when a PEM was implanted, the selective transportation of hydrogen ion towards the reaction site reduced the $N O_{X}$ formation rate and significantly enhanced the ammonia synthesis rate and efficiency (up to $91 \%$ ). Consequently, $\mathrm{NH}_{3}$ became the dominant nitrogenous product in the plasmaexposed electrolyte at lower axial distance between plasma electrode and electrolyte. Despite the current challenges, plasma technology will provide opportunities to direct the ammonia production industry toward a sustainable process in the future.

\section{Acknowledgments}

This work was supported by the National Research Foundation of Korea. This research was supported by leading Foreign Research Institute Recruitment Program through the National Research Foundation of Korea (NRF) funded by the Korea government (MSIT) (NRF-2016K1A4A3914113) and in part by Kwangwoon University, Seoul, Korea, 2019.

\section{References}

[1] Erisman J W, Sutton M A, Galloway J, Klimont Z and Winiwarter W 2008 Nature Geoscience 1 636

[2] Peng P, Chen P, Schiappacasse C, Zhou N, Anderson E, Chen D, Liu J, Cheng Y, Hatzenbeller R, Addy M et al. 2018 Journal of cleaner production 177 597-609

[3] Kumari S, Pishgar S, Schwarting M E, Paxton W F and Spurgeon J M 2018 Chemical Communications 54 13347-13350

[4] Patil B, Wang Q, Hessel V and Lang J 2016 Plasma assisted nitrogen fixation reactions Alternative Energy Sources for Green Chemistry (Royal Society of Chemistry Cambridge, UK) pp 296-338

[5] Galloway J N, Townsend A R, Erisman J W, Bekunda M, Cai Z, Freney J R, Martinelli L A, Seitzinger S P and Sutton M A 2008 Science 320 889-892

[6] Sakakura T, Uemura S, Hino M, Kiyomatsu S, Takatsuji Y, Yamasaki R, Morimoto M and Haruyama T 2018 Green Chemistry 20 627-633

[7] Haruyama T, Namise T, Shimoshimizu N, Uemura S, Takatsuji Y, Hino M, Yamasaki R, Kamachi T and Kohno M 2016 Green Chemistry 18 4536-4541

[8] Hawtof R, Ghosh S, Guarr E, Xu C, Sankaran R M and Renner J N 2019 Science advances 5 eaat5778

[9] Peng P, Chen P, Addy M, Cheng Y, Zhang Y, Anderson E, Zhou N, Schiappacasse C, Hatzenbeller R, Fan L et al. 2018 Chemical Communications 54 2886-2889

[10] Razon L F 2014 Environmental Progress and Sustainable Energy 33 618-624

[11] Rahemi N, Haghighi M, Babaluo A A, Jafari M F and Estifaee P 2013 Journal of Industrial and Engineering Chemistry 19 1566-1576

[12] Petitpas G, Rollier J D, Darmon A, Gonzalez-Aguilar J, Metkemeijer R and Fulcheri L 2007 International Journal of Hydrogen Energy 32 2848-2867

[13] Lu X, Naidis G, Laroussi M and Ostrikov K 2014 Physics Reports 540 123-166 
[14] Lu X, Keidar M, Laroussi M, Choi E, Szili E and Ostrikov K 2019 Materials Science and Engineering: R: Reports 138 36-59

[15] Bao D, Zhang Q, Meng F L, Zhong H X, Shi M M, Zhang Y, Yan J M, Jiang Q and Zhang X B 2017 Advanced Materials 291604799

[16] Peng P, Li Y, Cheng Y, Deng S, Chen P and Ruan R 2016 Plasma Chemistry and Plasma Processing 36 1201-1210

[17] Mehta P, Barboun P, Herrera F A, Kim J, Rumbach P, Go D B, Hicks J C and Schneider W F 2018 Nature Catalysis 1269

[18] Chen S, Perathoner S, Ampelli C, Mebrahtu C, Su D and Centi G 2017 Angewandte Chemie International Edition 56 2699-2703

[19] Kyriakou V, Garagounis I, Vasileiou E, Vourros A and Stoukides M 2017 Catalysis Today 286 $2-13$

[20] Kubota Y, Koga K, Ohno M and Hara T 2010 Plasma and Fusion Research $5042-042$

[21] Bak T, Nowotny J, Rekas M and Sorrell C 2002 International journal of hydrogen energy 27 991-1022

[22] Fiorenza R, Sciré S, D’Urso L, Compagnini G, Bellardita M and Palmisano L 2019 International Journal of Hydrogen Energy 44 14796-14807

[23] Nowotny J, Bak T, Nowotny M and Sheppard L 2006 The Journal of Physical Chemistry B 110 $18492-18495$

[24] Hainer A S, Hodgins J S, Sandre V, Vallieres M, Lanterna A E and Scaiano J C 2018 ACS Energy Letters 3 542-545

[25] Liu Z, Hou W, Pavaskar P, Aykol M and Cronin S B 2011 Nano letters 11 1111-1116

[26] Gómez-Ramírez A, Cotrino J, Lambert R and González-Elipe A 2015 Plasma Sources Science and Technology 24065011

[27] Xie D, Sun Y, Zhu T, Fan X, Hong X and Yang W 2016 RSC Advances 6 105338-105346

[28] Sugiyama K, Akazawa K, Oshima M, Miura H, Matsuda T and Nomura O 1986 Plasma chemistry and plasma processing 6 179-193

[29] Noxon J 1976 Geophysical Research Letters 3 463-465

[30] Eyde H S 1909 Journal of the Royal Society of Arts 57 568-576

[31] Goyal S S, Rains D W and Huffaker R C1988 Analytical Chemistry 60 175-179

[32] Ridnour L A, Sim J E, Hayward M A, Wink D A, Martin S M, Buettner G R and Spitz D R 2000 Analytical biochemistry $281223-229$

[33] Jiang H, Shao T, Zhang C, Li W, Yan P, Che X and Schamiloglu E 2013 IEEE Transactions on Dielectrics and Electrical Insulation 20 1101-1111

[34] Paneru R, Lamichhane P, Chandra Adhikari B, Ki S H, Choi J, Kwon J S and Choi E H 2019 AIP Advances $\mathbf{9} 075008$

[35] Rahman A, Yalin A, Surla V, Stan O, Hoshimiya K, Yu Z, Littlefield E and Collins G 2004 Plasma Sources Science and Technology 13537

[36] Lamichhane P, Ghimire B, Mumtaz S, Paneru R, Ki S H and Choi E H 2019 Journal of Physics D: Applied Physics $\mathbf{5 2} 265206$

[37] Ghimire B, Lamichhane P, Lim J S, Min B, Paneru R, Weltmann K D and Choi E H 2018 Applied Physics Letters 113194101

[38] Adhikari B, Adhikari M, Ghimire B, Park G and Choi E H 2019 Scientific reports 9 1-15

[39] Peng P, Cheng Y, Hatzenbeller R, Addy M, Zhou N, Schiappacasse C, Chen D, Zhang Y, Anderson E, Liu Y et al. 2017 International Journal of Hydrogen Energy 42 19056-19066

[40] Attri P, Kim Y H, Park D H, Park J H, Hong Y J, Uhm H S, Kim K N, Fridman A and Choi E H 2015 Scientific reports 59332

[41] Ghimire B, Szili E J, Lamichhane P, Short R D, Lim J S, Attri P, Masur K, Weltmann K D, Hong S H and Choi E H 2019 Applied Physics Letters 114093701

[42] Lukes P, Dolezalova E, Sisrova I and Clupek M 2014 Plasma Sources Science and Technology 23 015019 
[43] Kutasi K, Popović D, Krstulović N and Milošević S 2019 Plasma Sources Science and Technology 28095010

[44] Judée F, Simon S, Bailly C and Dufour T 2018 Water research 133 47-59

[45] Yue Y, Xian Y, Pei X and Lu X 2016 Physics of Plasmas 23123503

[46] Kong J, Lim A, Yoon C, Jang J H, Ham H C, Han J, Nam S, Kim D, Sung Y E, Choi J et al. 2017 ACS Sustainable Chemistry and Engineering 5 10986-10995

[47] Shi M M, Bao D, Wulan B R, Li Y H, Zhang Y F, Yan J M and Jiang Q 2017 Advanced Materials 291606550

[48] Zhou F, Azofra L M, Ali M, Kar M, Simonov A N, McDonnell-Worth C, Sun C, Zhang X and MacFarlane D R 2017 Energy and Environmental Science 10 2516-2520

[49] Singh A R, Rohr B A, Schwalbe J A, Cargnello M, Chan K, Jaramillo T F, Chorkendorff I and Nørskov J K 2017 Electrochemical ammonia synthesis, the selectivity challenge

[50] Ingels R and Graves D B 2015 Plasma Medicine 5 